\title{
EFFECT OF COLD STORAGE ON SOME BIOLOGICAL CHARACTERISTICS OF CORANUS AFRICANA EL-SEBAEY (HETEROPTERA : REDUVIIDAE)
}

\author{
EMAN I. A. EL-SEBAEY
}

Plant Protection Research Institute, ARC, Dokki, Giza, Egypt

\author{
(Manuscript received 5 June 2006)
}

Abstract

The Assian bug Coranus africana El-Sebaey (Heteroptera: Reduviidae) has recently been recorded in Egypt. It is occurred on various economic and wild plants at different locations. In the present work the effect of cold storage temperatures $\left(5,10,15^{\circ} \mathrm{C}\right)$ and $70 \%$ R.H, using the larval stage of Anagasta kuehniella Zell (Lepidoptera: Pyralidae) as a prey were studied. The storage periods of five nymphal stages, male and female at $15^{\circ} \mathrm{C}$ averaged $5.1,6.43,7.3,8.9,10.01,10.31$ and 9.79 weeks respectively. They were longer than storage periods at 10 and $5^{\circ} \mathrm{C}$. Parameters of reporoductive biology, age specific survivorship, fecundity, egg hatchability and food consumption were aiso influenced by storage temperatures.

\section{INTRODUCTION}

All reduviids are predators except tritomins, most of them appear to orient to their prey visually. Valuable sources on reduviid biology include the works of Miller (1971), based on the fauna of Zimbabwe and North America; Putchkov (1987) on the fauna of the Ukraine and Louis (1974) on the fauna of Chana. The avaluable biological informations of the Egyptian reduviid are given by Awadalla et al. (1990) Afifi et al. (1993a,b); and EL-Sebaey (1996, 1998, 2001a).

Coranus africana EL-Sebaey (Heteroptera: Reduviidae) has recently been registered in Egypt by El-Sebaey (2002). The predator was reported in various economic crops as cotton, tomato, clover, maize, as well as several wild desert plants. Several biological aspects were studied by using two common cotton pests in Egypt, Spodoptera littoralis (Bosid.) and Agrotis ipsilon Rott. and other stored product pests (Anagasta kuehniella Zell. and Corcyra cephalonica Stt. as laboratory prey (El-Sebaey 2001 b, El-Sebaey \& El-Bishry 2001). Also the effect of rearing space on the development were determined by El-Sebaey and El-Shazly (2002). Field trails to evalute the predators in different economic crops have been measured in Egypt by ElSebaey et al. (2002, 2004) and El-Sebaey \& Abd El-Wahab (2003).

The objective of the present study is to determine the effect of cold storage on some biological aspects of $C$. africana to be used in biological control programs at any time. 


\section{MATERIALS AND METHODS}

A laboratory cultures of Coranus africana (Heteroptera: Reduviidae) were collected from economic crops as tomato, clover, cotton and desert grasses. The predator was recorded at Fayoum and Giza Governorates. A detailed description of rearing tecknique was given by El-Sebaey (2001b), and El-Sebaey \& El-Bishry (2001).

A culture of Anagasta kuehniella (Lepidoptera: Pyralidae) was initated by moths emerged from infested flour obtained from mills. They were kept under laboratory constant condition $27^{\circ} \mathrm{C}$ and $65 \%$ R.H. A methods adopted from El-Sebaey (1996, 1998) were employed.

Biological experiments:

Experiments were conducted using incubations adjusted at $5^{\circ} \mathrm{C}, 10^{\circ} \mathrm{C}$ and $15^{\circ} \mathrm{C}$ $\pm 1^{\circ} \mathrm{C}$ and $70 \%$ R. H.

The newly emergence of each nymphal stage was immediately isolated from stock cultures in the individual rearing tube (100 tubes are replicated for each experiment. Each tube $(1.5 \mathrm{~cm}$. diameter $X 3.5 \mathrm{~cm}$. height with a perforated cover) was provided with a disc of filter paper and sufficient larvae of $A$. kuehniella then kept continuously at storage temperatures $5^{\circ} \mathrm{C}, 10^{\circ} \mathrm{C}$ and $15^{\circ} \mathrm{C} \pm 1^{\circ} \mathrm{C}$ and $70 \% \mathrm{R}$. H. Daily inspections were carried out to record molting and mortality of the nymphs. Also the newly emerged adults were collected and paired. One couple in rearing cage (20 cages as replicates for each experiment). Each cage $(2.5 \mathrm{~cm}$ diameter and $5 \mathrm{~cm}$ height), was provided with a filter paper disc and covered with a perforated plastic cover. A supply of sufficient prey larvae were added daily to each cage. The oviposited eggs were examined daily, counted transferred, to the incubation cages $(2.5 \mathrm{~cm}$. diameter $X 5 \mathrm{~cm}$. height) and provided with a filter paper disc and covered with a perforated plastic cover, at a rate of 10eggs/cage (20 cages were used replicates for each experiment). Daily inspection took place to count the moulting nymphs and to estimate the percentage of hatchability.

The weekly consumed prey by each nymph and adult in the experiments were recorded as reported by El-Sebaey \& El-Bishry (2001).

\section{RESULTS AND DISCUSSION}

\section{1-Storage at $5^{\circ} \mathrm{C}$ :}

Data in (Table 1) indicated that the survival rate at $5^{\circ} \mathrm{C}$ of first nymphal instar was $84.4 \%$ at the first week and decreased sharply to reach $57.8 \%$ and $49.9 \%$ in storage at second and third weeks. For the second and third instar this rate decreased gradually from $90.5 \%$ and $95.24 \%$ at the $1^{\text {st }}$ week to reach $13.3 \%$ and 14.3 at the sixth and seventh week, respectively. The survival rate of fourth and fifth 
instars increased in all storage weeks. It was $100 \%$ in the first week and decreased gradually to reach $23.81 \& 27.59 \%$, respectively in the $7^{\text {th }}$ week; the storage period extend to $8^{\text {th }}(4.77 \%)$ and $9^{\text {th }}(3.4 \%)$, respectively.

The total storage periods of five nymphal instars were $3.21,4.13,5.08,5.85$ and 6.03 weeks, resprectively. In second storage week, second, third and fourth instars developed by the presence of $4.8,10.1$ and $14.3 \%$, respectively.

The males and females lived up to $9^{\text {th }}$ and $10^{\text {th }}$ weeks after adults emergence, with highestes survival (100\%) in storage for first two weeks and declined gradually. The female didn't deposite any eggs during it's life span ( 7.39 weeks) at $5^{\circ} \mathrm{C}$.

All stages of $C$. africana stored successfuly at $5^{\circ} \mathrm{C}$ when reared on larvae of $A$. kuehniella. The mean weekly consumption rates of nymphal stage increased gradually with the development of various instars (Table 1).

The number of $A$. kuehniella larvae consumed in storage at first week by the five nymphal, female and male were in respective 1.41, 1.44, 1.64, 1.69, 1.76, 1.72 and 1.67 larva/week. These rates decreased gradually with increase of the storage weeks.

\section{2-Storage at $10^{\circ} \mathrm{C}$ :}

Storage period of $C$. africana varied with the stage at $10^{\circ} \mathrm{C}$ (Table 2). All first two stadia lived up to the end of storage first week, the survival rate was decreased sharply to the end of storage period. All the last three nymphal stages and male lived up to the second week; also all females lived to the third week, the survival rate was decreased gradually (Table 2 ).

The storage total period of the five stadia, female and male were 4.01, 4.1, $6.16,6.89,7.42,8.82$ and 7.71 weeks, respectively. During storage second week, the last three stadia developed by the presence of $0.3,10.1$ and $20.1 \%$, repectively; also the fourth stadium developed by $22 \%$ in storage third week. The female did not lay any eggs during it's life span.

C. africana stored successfully at $10^{\circ} \mathrm{C}$ when reared on $A$. kuhniella larvae. Generally, the weekly number of consumed larvae increased with the development of various instars. The number of larvae consumed in storage first week by the five nymphal stages, female and male in respective were $0.5,0.7,1.1,1.75,1.8,1.9$ and 1.81 larva/week. These rate decreased gradullay till storage period end (Table 2).

\section{3- Storage at $15^{\circ} \mathrm{C}$ :}

Data summarized in (Table 3) showed that all stages of C. africana at $15^{\circ} \mathrm{C}$ lived up to the end of third week except the females lived up to $5^{\text {th }}$ week after emergence. The survival rates of all stadia and adults were decreased gradually to 
the end of storage. On the other hand, the storage period were $5.1,6.43,7.3,8.9$, $10.01,10.31,9.79 /$ week, respectively.

All nymphal stages except first stage developed during storage second week by $6.67,10.2$ and $20.1 \%$, respectively.

The weekly rate of deposited eggs/o (Table 3) varied during the successive weeks of oviposition. This rate attained its highest value during the $4^{\text {th }}$ and $5^{\text {th }}$ weeks (16.01 and 16.69 eggs, respectively). This rate decreased gradually till $10^{\text {th }}$ week of storage period.

This reduviid stored successfully at $15^{\circ} \mathrm{C}$ when reared on larvae of $A$. kuehniella. The mean weekly consumption rates of nymphs and adult stages increased gradually with the development of various instars (Table 3 ). The numbers of larvae consumed in first storage week were1.1, 1.46, 1.6, 2.2, 2.3, 2.32 and 2.21 larvae/week, respectively. These rates increased gradually till half time of storage period and then decreased gradually .

At all storage temperatures $\left(5,10\right.$ and $\left.15^{\circ} \mathrm{C}\right)$, the eggs didn't hatch, and the storage temperatures affected incubation period and hatchability.

The storage period varied with temperatures used (Table 1, 2, 3). Nymphal storage periods varied with temperatures used; being significantly longer at $15 \mathrm{C}^{\circ}$ in each instar than at $10 C^{\circ}$ and $5 C^{\circ}(P>0.05)$. The nymphal survival rate also varied with temperatures used in storage with significant differences. Also the weekly consumption rate existed had significantly differences $(P>0.05)$.

. All the biological activity of adults varied with storage temperatures used. The oviposition periods, egg-laying activity and survivorship rate existed significantly differed and being better at $15 C^{\circ}$. Also significant differences $(P>0.05)$ existed between the consumption weekly rates of females and males and between three temperatures.

C. africana reared at $30 \mathrm{C}^{\circ}$ and $70 \% \mathrm{R}$. H. on different prey (Anagasta kuehniella Zell, Corcyra cephalonica Stt., Spodoptera littoralis (Bosid.) and Agrotis ypsilon Rott). When reared on first prey, the nymphal development was the shortest and the survival rate was the highest. On the other hand, all biological activity of adults varied with prey used, the oviposition period, egg-laying activity and survivorship rate were best on the same prey. Also the incubation period and the hatchability rate of deposited eggs were affected by the prey used (El-Sebaey 2001a and EL-Sebaey \& El-Bishry, 2001).

The methodology of mass rearing determined when studied the biological activity of nymphal stages and adults by rearing this predator in different size of containers at $30 \mathrm{C}^{\circ}$ and $70 \%$ R. H. on A. kuehniella. (El-Sebaey \& El-Shazly, 2002). 


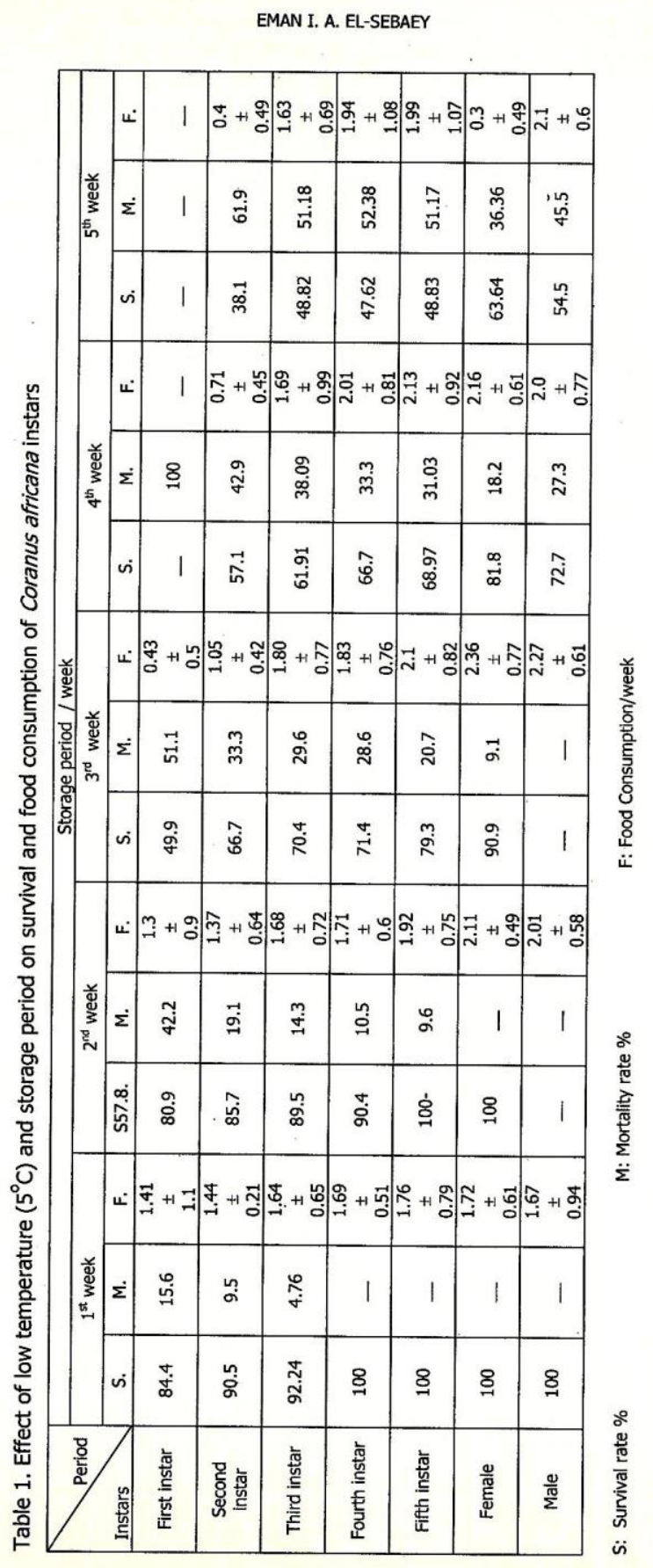




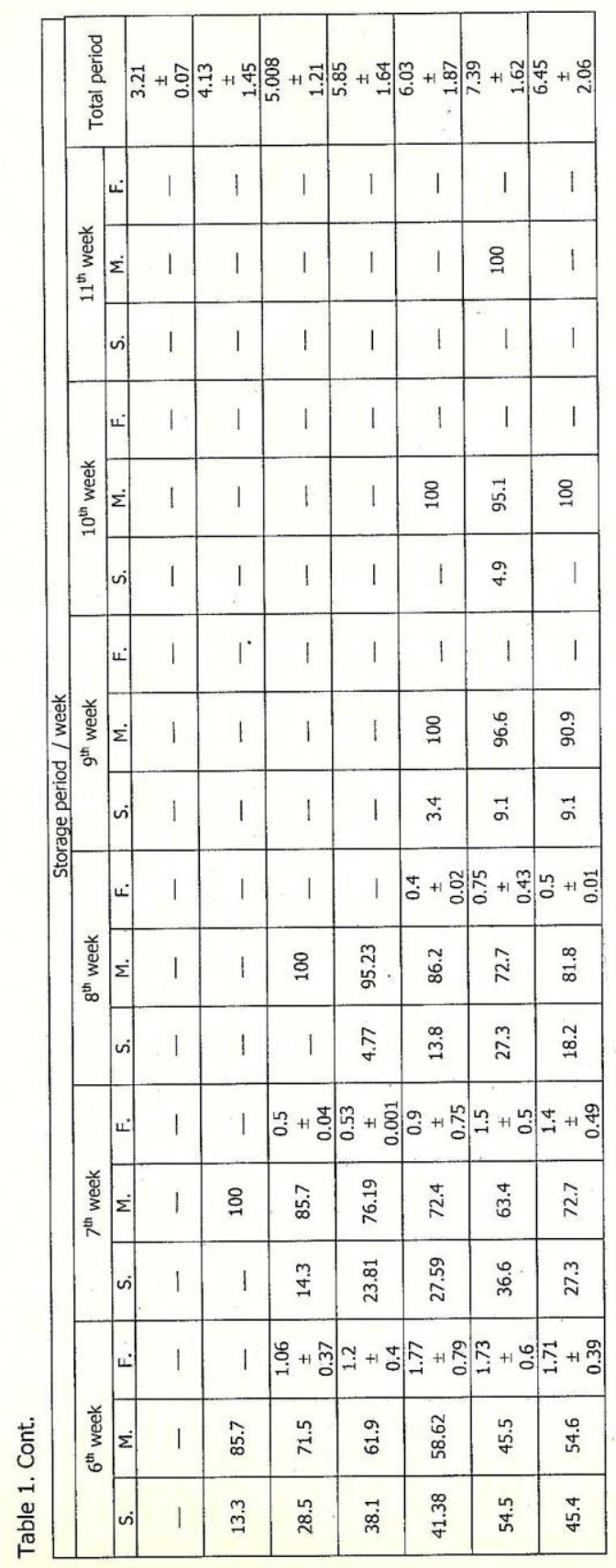




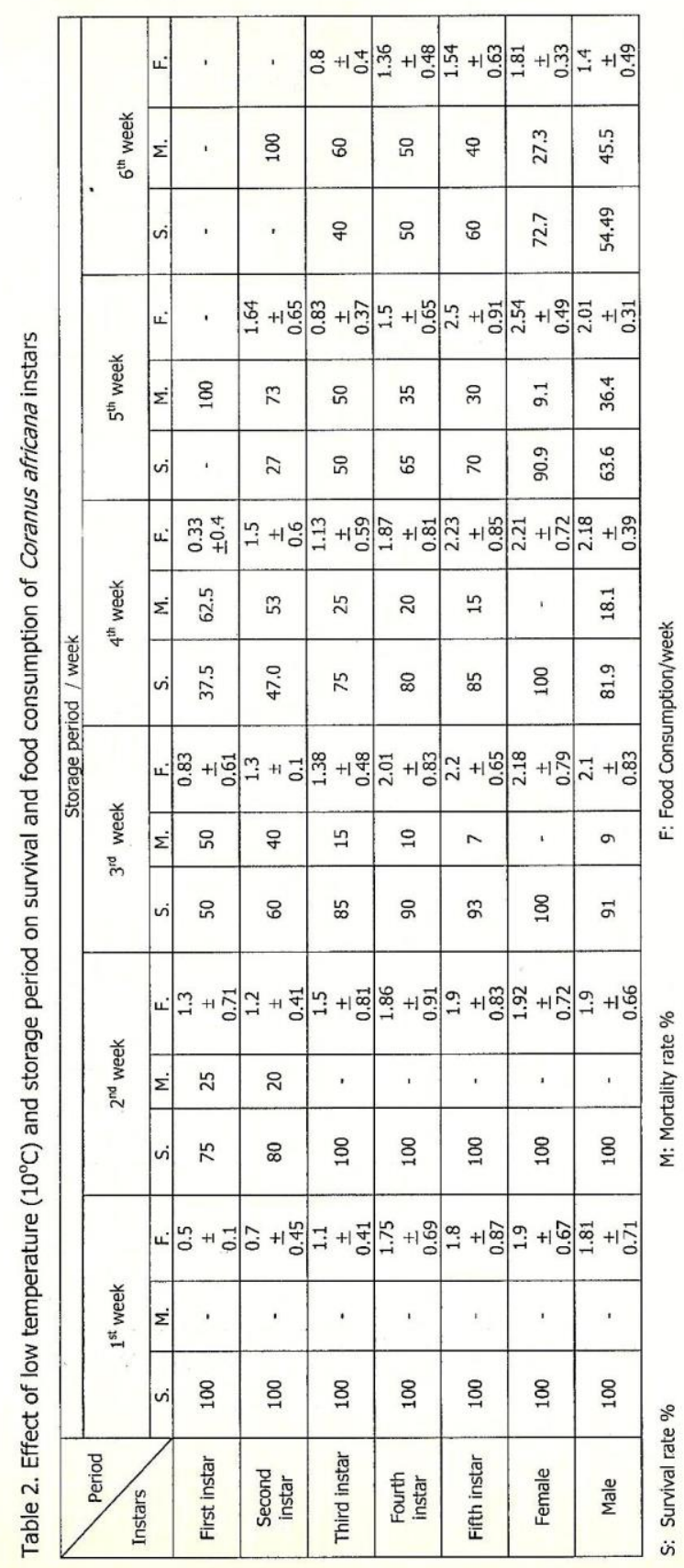




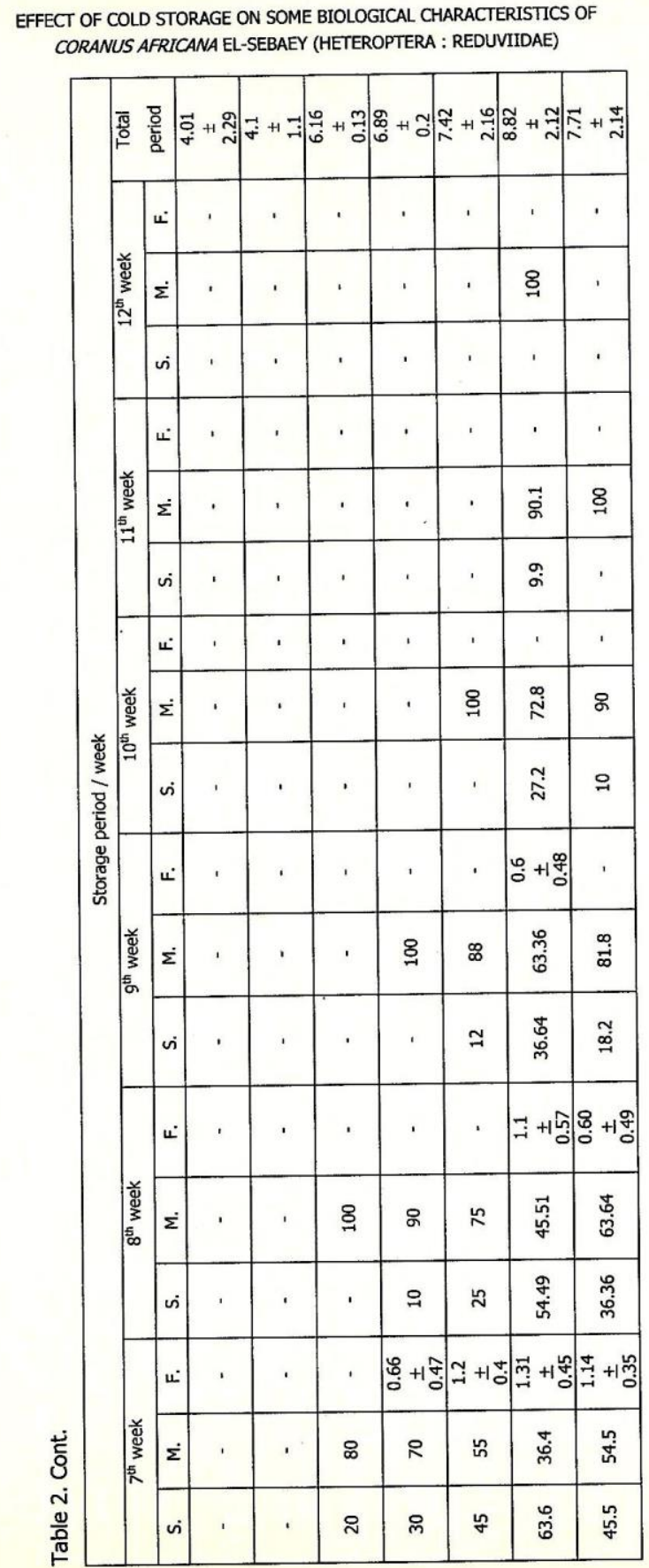




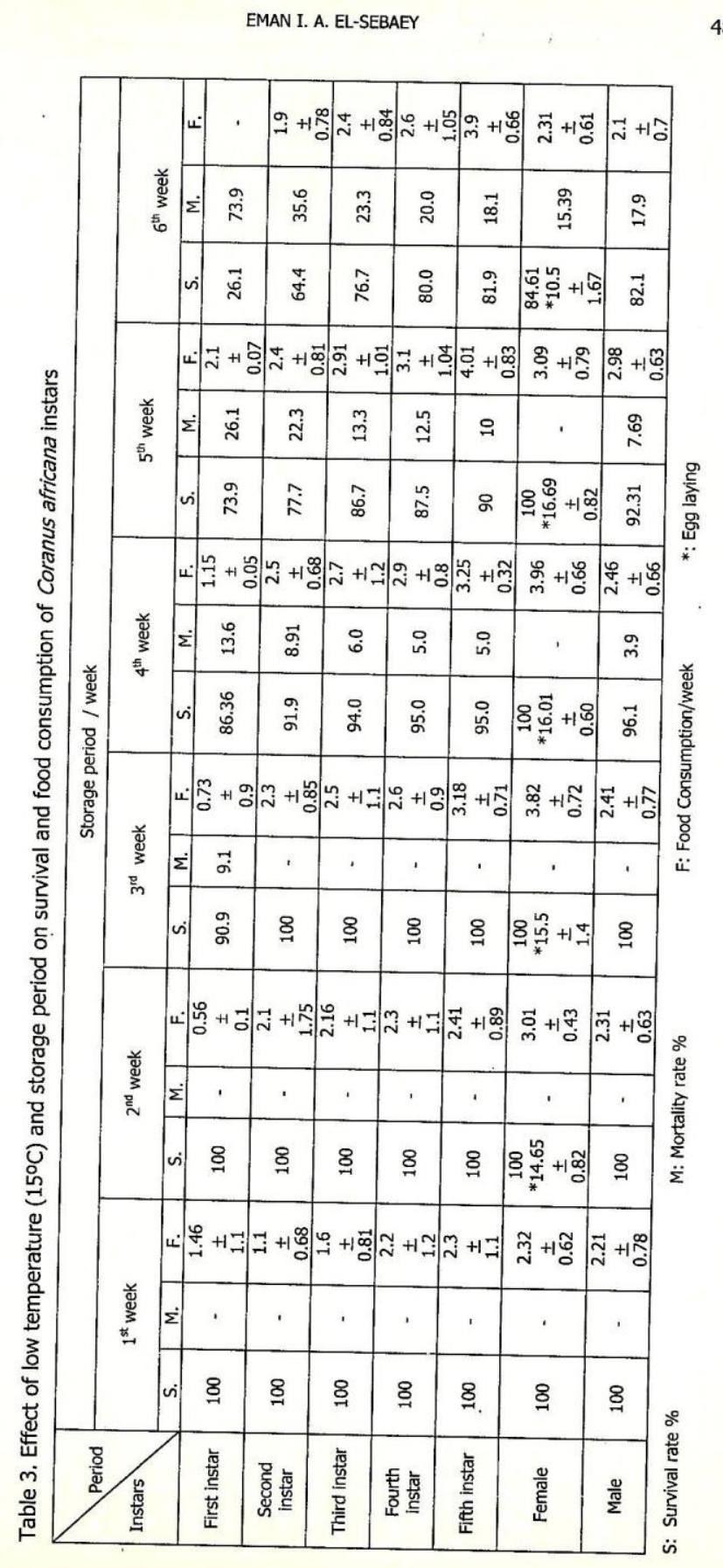




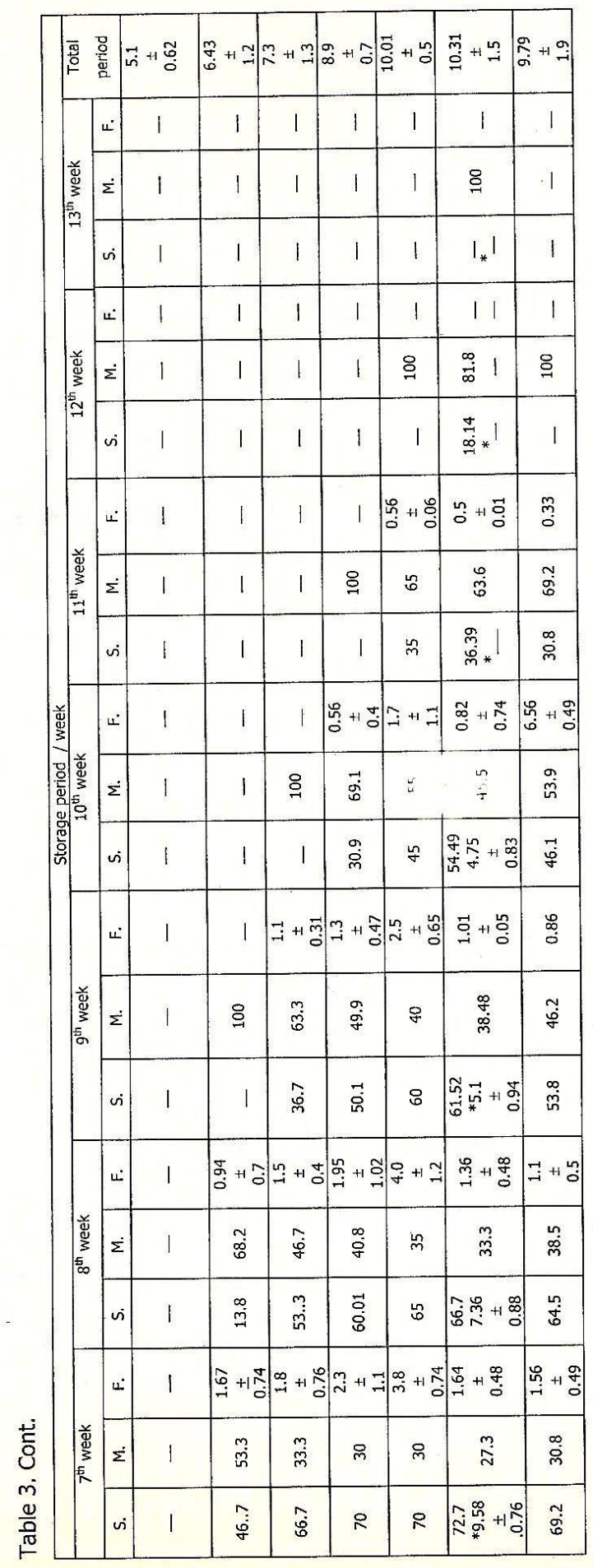




\section{REFERENCES}

1. Afifi, A. I., K. T. Awadalla, I. I. A. El-Sebaey and M. F. S., Tawfik. 1993a. Biology and description of immature stages of Coranus angulatus Stal (Hemiptera:Reduviidae). Egypt. J. Biol Pest. Cont. 3 (2): 157-158.

2. Afifi, A. I., K. T., Awadalla, M. F. S. Tawfik, and I. I. A. El-Sebaey. 1993b. Description of immature stages of Reduvius nigricans Klug (Hem.: Reduviidae) together with certain biological observation. Bull. Ent. Soc. Egypt. ZI: 119-130.

3. Awadallah, K. T, A. I. Afifi and I. I. A. El-Sebaey. 1990. The biology of the reduviid, Alloeocranum biannulipes (Mont \& Sign.), a predator of stored product insect pests. Bull. Soc. Ent. Egypt, 69: 196-181.

4. El-Sebaey, I. I. A. 1996. Description and biological studies on different developmental stages of Vachira natolica Stal (Hemiptera-HeteropteraReduviidae). Egypt. J. Biol. Pest. Cont. 6 (2): 177-184.

5. El-Sebaey, I. I. A. 1998. Biological and morphological studies on Coranus aegyptius (F) (Hemiptera: Reduviidae). Egypt. J. Agric. Res., 76 (3): 933-945.

6. El- Sebaey, I. I. A. 2001a. Biology and predation rates of certain adult reduviids (Heteroptera: Reduviidae). Egypt J. Biol. Pest Cont., 11 (1): 15-23.

7. El- Sebaey, I. I. A. 2001b. Biology and predation rates of the, assassin bug, Coranus africana El-Sebaey (Heteroptera: Reduviidae) on the cotton pests, Spodoptera littoralis (Bosid.) and Agrotis ypsilon Rott. Bull. Fac. Agric., Cairo. Univ., 52: 655-668.

8. EL-Sebaey, I. I. A. 2002. Coranus africana sp. Nov., A new harpactorine (Reduviidae-Hemiptera) from Egypt. Egypt. J. Agric. Res. 80 (1): 211-217.

9. El- Sebaey, I. I. A and M. H. El-Bishry. 2001. Biological aspects and predation of Coranus africana El-Sebaey on the Laboratory prey Anagasta kuehniella and Corcyra cephalonica. Egypt. Jou. Bio. Pest. Cont., 11(2): 57-62.

10. El- Sebaey, I. I. A and M. M. El-Shazly. 2002. Effect of containers size on the development and mass rearing of the predatory bug, Coranus africana (Hemiptera: Reduviidae). Proc. of the $2^{\text {nd }}$ conf. of Ent., pp, 133-145.

11. El-Sebaey, I. I. A., H. A. Abd. El- Wahab and S. A. Ibrahim. 2002. Suppression of whitefly Bemisia tabaci (Genn.) with agugmentative release of Assassin Bug, Coranus africana El-Sebaey (Het.; Reduviidae) in cucumber green house. J. Union Arab Bio; Cairo, 17 (A) Zoology: 197-205.

12. El- Sebaey, I. I. A and H. A. Abd El- Wahab. 2003. Suppression of Bemisia tabaci (Genn.), Aphis gossypii Glov. and Spodoptera littoralis (Bosid) by Coranus africana El-Sebaey (Het.: Reduviidae) in tomato field. Bull. Fac. Agric. Cairo Univ., 54 (1) 141-150. 
13. El-Sebaey I. I. A., H. A. Abd El-Wahab and S. A. Ibrahim. 2004. The role of the predatory bug Coranus africana El-Sebaey (Heteroptera: Reduviidae) in the suppression of different infestation levels of the whitefly, Bemisia tabaci in tomato field. Al-Azhar J. Agric. Res., Vol. 39:55-60.

14. El- Sebaey, I. I. and M. M. El-Shazly 2002. Effect of Containers size on the development and mass rearing of the predatory bug, Coramus Africana (Hamriptera : Reduviidae). Proc, of $2^{\text {nd }}$ Conf. of Ent. March 27, 2002, pp. 133145.

15. Louis, S. 1974. Biology of Reduviidae of cocoa farms in Ghana. Am. Midl. Nat., 91: $68-80$.

16. Miller, N. C. E. 1971. The biology of the Heteroptera, $2^{\text {nd }}$ ed., rev. Hampton, Classey. xiii, 206pp.

17. Putchkov, P. 1987. Assassin bugs in the fauna of the Ukraine, Vol. 21. P.5. Naukova Dumka, kiev. 284pp. 
تأثير درجات العـرارة المنففضة على الظواهر البيولوجية للمفترس Coranus africana El-Sebaey إيمان إبراهيم عبد الرحمن السباعى معز بحوث وقاية النباتات ـ مركز البحوث الزراعية ـ دقى - جيزة - مصر

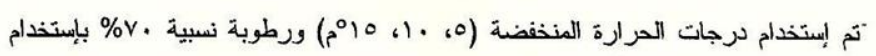
يرقات فراش دقيق البحر الأبيض المتوسط Anagasta kuehniella Zell كعائل معملى لتخزين

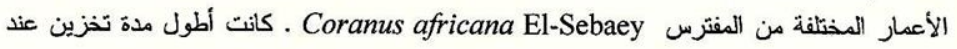

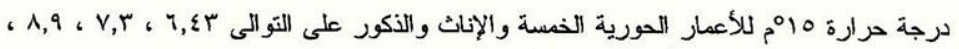

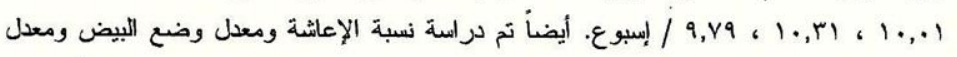

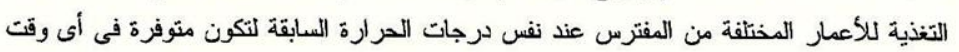
لإستخدامها فى برامج المكافحة المنكاملة. 